\title{
Study of hysterolaparoscopy in the evaluation of infertility
}

\author{
Shilpa G B
}

Consultant Reproductive Medicine, Shilpa Diagnostics, Davanagere-577004, Karnataka, INDIA.

Email: shilpagb@yahoo.com

Abstract Background: World health organisation defined infertility as failure to conceive after 12 months or more of regular unprotected sexual intercourse. Combining hysteroscopy with laparoscopy has become a standard tool of evaluation though the absolute role of hysteroscopy in unexplained infertility is yet to be elucidated. The purpose of present study is to assess the role of hysterolaparoscopy in diagnosis and treatment of female infertility at a tertiary hospital. Material and Methods: This was a prospective, observational study, conducted in Department of obstetrics and gynaecology, in patients with primary or secondary infertility, underwent hysterolaparoscopy. Results: During study period total 112 patients satisfying study criteria underwent hysterolaparoscopy. $78 \%$ patients had primary infertility while rest $22 \%$ had secondary infertility. Most patients were from 26-30 years age group (35\%) followed by 21-25 years age group (32\%). In $46 \%$ patients no abnormality noted in laparoscopy (primary infertility- $47 \%$ and secondary infertility- $44 \%$ ). In patients with primary infertility PCOS (20\%), fallopian tube blockage (14\%) and ovarian cyst (9\%) were main findings. Hysteroscopy was normal in $81 \%$ patients. (primary infertility- $80 \%$ and secondary infertility- $84 \%$ ). In patients with primary infertility uterine anomaly such as septate uterus/bicornuate uterus/submucous fibroid (10\%) was most common finding followed by endometrial polyp (7\%). PCOS drilling (20\%), successful tubal cannulation(10\%) and ovarian cystectomy $(9 \%)$ were most common interventions in total and primary infertility patients. In secondary infertility patients hysteroscopic polypectomy and dilatation curettage were also common interventions done. No post-op complication, morbidity or mortality noted in present study. Conclusion: Hysterolaparoscopy is a definitive diagnostic tool for evaluation of female infertility. Hysterolaparoscopy is an effective, safe, reliable and minimal invasive tool in comprehensive evaluation of infertility and also good therapeutic intervention by experienced hands.

Keywords: infertility, hysterolaparoscopy, hysteroscopy, laparoscopy.

\section{*Address for Correspondence:}

Dr Shilpa G B, consultant Reproductive medicine, Shilpa Diagnostics, Davanagere-577004, Karnataka, INDIA.

Email: shilpagb@yahoo.com

Received Date: 20/11/2019 Revised Date: 19/12/2019 Accepted Date: 11/01/2020

DOI: https://doi.org/10.26611/10121536

This work is licensed under a Creative Commons Attribution-NonCommercial 4.0 International License. (cc)) EY-NC

\begin{tabular}{|l|l|}
\hline \multicolumn{2}{|c|}{ Access this article online } \\
\hline Quick Response Code: & Website: \\
\hline & www.medpulse.in \\
\cline { 2 - 2 } & \\
\cline { 2 - 2 } & \\
\hline
\end{tabular}

\section{INTRODUCTION}

Infertility is one of the most important and underappreciated reproductive health problems in developing countries. Infertility is frequently considered a personal tragedy and a curse for the couple, affecting the entire family. World health organisation defined infertility as failure to conceive after 12 months or more of regular unprotected sexual intercourse. The prevalence of infertility ranges from $3.5 \%$ to $16.7 \%$ in more developed nations and from $6.9 \%$ to $9.3 \%$ in less developed nations, with an estimated overall median prevalence of $10 \%$ of reproductive age couples. ${ }^{1,2}$ It can be subdivided into primary infertility, that is, no prior pregnancies, and secondary infertility, referring to infertility following at least one prior conception. The aetiology of female infertility can be broadly divided into ovulation disorders, uterine abnormalities, tubal obstruction, peritoneal factors and cervical factors. Unexplained infertility is infertility that is idiopathic in the sense that its cause remains unknown even after an infertility work-up, usually including semen analysis in the men and assessment of ovulation and fallopian tubes in the woman. The 
advantages of endoscopic surgery are preciseness, superior haemostasis, less tissue handling, less pain, no cosmetic issue, short convalescence and quicker recovery. Combining hysteroscopy with laparoscopy has become a standard tool of evaluation though the absolute role of hysteroscopy in unexplained infertility is yet to be elucidated. ${ }^{3,4}$ While some researcher consider hysterolaparoscopy as an effective tool in investigation of unexplained infertility patients, as early therapeutic interventions or early decisions for artificial reproductive technique can be taken place. ${ }^{5}$ The purpose of present study is to assess the role of hysterolaparoscopy in diagnosis and treatment of female infertility at a tertiary hospital.

\section{MATERIAL AND METHODS}

This was a prospective, observational study, conducted in Department of obstetrics and gynaecology, Shilpa Diagnostics, Davanagere. Study period was from January 2019 to December 2019. Institutional ethical committee approval was obtained for present study.

\section{Inclusion Criteria -}

Patients with primary or secondary infertility, willing to participate in study.

\section{Exclusion Criteria -}

1. Patients with infectious disorder like acute PID or active TB.

2. Couples with male factor infertility.

3. Patient with major medical disorder like cardiovascular, respiratory or immune disorders, patient unfit for surgery.

Procedure was explained to patients and a written informed consent was taken. A complete clinical history and examination was carried out. All basic routine investigations with some special hormonal investigation such as hemoglobin percentage, total WBC count, DLC, ESR, urine routine, serological test for Syphilis, HIV, HbsAg, Blood grouping and Rh typing, hormonal tests such as FSH, LH, prolactin levels and thyroid profile was done. A baseline USG abdomen and TVS was done in each patient. With pre-op preparation, patients were posted for diagnostic and if required therapeutic hysterolaparoscopy procedure, under general anaesthesia. Intraoperative findings were noted. Standard post-operative care was given to all patients. All clinical findings and details were recorded in case proforma. Statistical analysis was done using descriptive statistics.

\section{RESULTS}

During study period total 112 patients satisfying study criteria underwent hysterolaparoscopy. $78 \%$ patients had primary infertility while rest $22 \%$ had secondary infertility.

\begin{tabular}{ccc}
\multicolumn{3}{c}{ Table 1: Infertility type } \\
\hline Type & Number & $(\%)$ \\
\hline Primary & 87 & $78 \%$ \\
Secondary & 25 & $22 \%$ \\
\hline
\end{tabular}

Most patients were from 26-30 years age group (35\%) followed by 21-25 years age group (32\%). In patients with primary infertility, most patients were from 21-25 years age group (40\%) followed by $26-30$ years age group (33\%). In secondary infertility patients, $31-35$ years age group (48 \%) was most common followed by $21-25$ years age group (40 \%).

Table 2: Age distribution

\begin{tabular}{ccccccc}
\hline Age (years) & $\begin{array}{c}\text { Primary Infertility } \\
(\mathbf{n}=87)\end{array}$ & $(\%)$ & Secondary infertility $(\mathbf{n}=\mathbf{2 5})$ & (\%) & Total & $(\%)$ \\
\hline $21-25$ & 35 & $40 \%$ & 1 & $4 \%$ & 36 & $32 \%$ \\
$26-30$ & 29 & $33 \%$ & 10 & $40 \%$ & 39 & $35 \%$ \\
$31-35$ & 16 & $18 \%$ & 12 & $48 \%$ & 28 & $25 \%$ \\
$>36$ & 7 & $8 \%$ & 2 & $8 \%$ & 9 & $8 \%$ \\
\hline
\end{tabular}

Most patients had duration of infertility less than 5 years (49\%), followed by 6-10 years (32\%). Most common duration in primary infertility patients was less than 5 years $(53 \%)$ while in secondary infertility patients it was 6-10 years $(40 \%)$.

Table 3: Duration of infertility

\begin{tabular}{ccccccc}
\hline Duration (years) & Primary Infertility $(\mathbf{n}=\mathbf{8 7})$ & $(\%)$ & Secondary infertility $(\mathbf{n}=\mathbf{2 5})$ & $(\%)$ & Total & $(\%)$ \\
\hline $1-5$ & 46 & $53 \%$ & 9 & $36 \%$ & 55 & $49 \%$ \\
$6-10$ & 26 & $30 \%$ & 10 & $40 \%$ & 36 & $32 \%$ \\
$11-15$ & 14 & $16 \%$ & 6 & $24 \%$ & 20 & $18 \%$ \\
$>16$ & 1 & $1 \%$ & 0 & $0 \%$ & 1 & $1 \%$ \\
\hline
\end{tabular}


In $46 \%$ patients no abnormality noted in laparoscopy (primary infertility- $47 \%$ and secondary infertility- $44 \%$ ). In patients with primary infertility PCOS $(20 \%)$, fallopian tube blockage $(14 \%)$ and ovarian cyst $(9 \%)$ were main findings. In secondary infertility patients PCOS (20\%), fallopian tube blockage (16\%) and peritubular adhesion (8\%) were common findings noted.

Table 4: Laparoscopic findings*

\begin{tabular}{|c|c|c|c|c|c|c|}
\hline Findings & $\begin{array}{c}\text { Primary Infertility ( } \mathrm{n}= \\
\text { 87) }\end{array}$ & (\%) & $\begin{array}{c}\text { Secondary infertility (n } \\
=25)\end{array}$ & $(\%)$ & Total & $(\%)$ \\
\hline Normal & 41 & $47 \%$ & 11 & $44 \%$ & 52 & $46 \%$ \\
\hline PCOS & 17 & $20 \%$ & 5 & $20 \%$ & 22 & $20 \%$ \\
\hline Unilateral fallopian block & 8 & $9 \%$ & 4 & $16 \%$ & 12 & $11 \%$ \\
\hline Ovarian cyst & 8 & $9 \%$ & 1 & $4 \%$ & 9 & $8 \%$ \\
\hline Peritubular adhesion & 6 & $7 \%$ & 2 & $8 \%$ & 8 & $7 \%$ \\
\hline Tubovarian mass & 5 & $6 \%$ & 1 & $4 \%$ & 6 & $5 \%$ \\
\hline Dermoid cyst & 5 & $6 \%$ & 1 & $4 \%$ & 6 & $5 \%$ \\
\hline Bilateral fallopian block & 4 & $5 \%$ & 0 & $0 \%$ & 4 & $4 \%$ \\
\hline Adhesions & 4 & $5 \%$ & 0 & $0 \%$ & 4 & $4 \%$ \\
\hline Endometriotic spot & 4 & $5 \%$ & 1 & $4 \%$ & 5 & $4 \%$ \\
\hline Bicornuate uterus & 3 & $3 \%$ & 0 & $0 \%$ & 3 & $3 \%$ \\
\hline Subserosal fibroid & 3 & $3 \%$ & 0 & $0 \%$ & 3 & $3 \%$ \\
\hline Endometrial cyst & 3 & $3 \%$ & 1 & $4 \%$ & 4 & $4 \%$ \\
\hline Uterus didelphys & 1 & $1 \%$ & 0 & $0 \%$ & 1 & $1 \%$ \\
\hline
\end{tabular}

Hysteroscopy was normal in $81 \%$ patients. (primary infertility- $80 \%$ and secondary infertility- $84 \%$ ). In patients with primary infertility uterine anomaly such as septate uterus/bicornuate uterus/submucous fibroid (10\%) was most common finding followed by endometrial polyp (7\%). While in secondary infertility patients endometrial polyp (8\%) and intrauterine adhesions were common findings.

Table 5: Hysteroscopy findings

\begin{tabular}{ccccccc}
\hline Hysteroscopy findings & $\begin{array}{c}\text { Primary Infertility } \\
(\mathbf{n}=\mathbf{8 7})\end{array}$ & $\mathbf{( \% )}$ & $\begin{array}{c}\text { Secondary infertility } \\
(\mathbf{n}=\mathbf{2 5})\end{array}$ & $\mathbf{( \% )}$ & Total & (\%) \\
\hline Normal & 70 & $80 \%$ & 21 & $84 \%$ & 91 & $81 \%$ \\
Uterine anomaly & 9 & $10 \%$ & 0 & $0 \%$ & 9 & $8 \%$ \\
Endometrial polyp & 6 & $7 \%$ & 2 & $8 \%$ & 6 & $5 \%$ \\
Intrauterine adhesions & 1 & $1 \%$ & 1 & $4 \%$ & 4 & $4 \%$ \\
Cervical stenosis & 1 & $1 \%$ & 1 & $4 \%$ & 2 & $2 \%$ \\
\hline
\end{tabular}

PCOS drilling (20\%), successful tubal cannulation(10\%) and ovarian cystectomy (9\%) were most common interventions in total and primary infertility patients. In secondary infertility patients hysteroscopic polypectomy and dilatation curettage were also common interventions done. No post-op complication, morbidity or mortality noted in present study.

Table 6: Surgical Intervention

\begin{tabular}{|c|c|c|c|c|c|c|}
\hline Procedures & Primary Infertility $(\mathrm{n}=87$ ) & $(\%)$ & Secondary infertility $(n=25)$ & $(\%)$ & Total & $(\%)$ \\
\hline Only diagnostic & 36 & $41 \%$ & 11 & $44 \%$ & 47 & $42 \%$ \\
\hline PCOS drilling & 17 & $20 \%$ & 5 & $20 \%$ & 22 & $20 \%$ \\
\hline Successful tubal cannulation & 9 & $10 \%$ & 2 & $8 \%$ & 11 & $10 \%$ \\
\hline Dilatation and curettage & 6 & $7 \%$ & 2 & $8 \%$ & 8 & $7 \%$ \\
\hline Dermoid cystectomy & 5 & $6 \%$ & 1 & $4 \%$ & 6 & $5 \%$ \\
\hline Adhesiolysis & 4 & $5 \%$ & 0 & $0 \%$ & 4 & $4 \%$ \\
\hline Endometriod /chocolate Cystectomy & 3 & $3 \%$ & 1 & $4 \%$ & 4 & $4 \%$ \\
\hline Hysteroscopic resection of septum & 2 & $2 \%$ & 0 & $0 \%$ & 2 & $2 \%$ \\
\hline Cervical dilatation & 1 & $1 \%$ & 0 & $0 \%$ & 1 & $1 \%$ \\
\hline Myomectomy & 1 & $1 \%$ & 0 & $0 \%$ & 1 & $1 \%$ \\
\hline
\end{tabular}

*- A patient may underwent one or more surgical intervention/s. 


\section{DISCUSSION}

Routine examination and diagnostic procedures are not enough to evaluate pelvic pathology of infertile women. Uterine and tubal factors can effectively diagnosed by endoscopic approach. Hysterolaparoscopy provides opportunity to understand the levels of infertility among couples which is crucial in order to improve the clinical management of infertility. ${ }^{6}$ Most patients were from 26-30 years age group ( $35 \%$ ) followed by $21-25$ years age group $(32 \%)$. Increasing lifestyle choices, stress and later age of marriage have made occurrence of Infertility higher than couple of decades ago. ${ }^{7}$ Stressful and exhausting lifestyle is a major cause of infertility in young age as depicted by the study as $26-30$ years. The prevalence of primary infertility was higher among women aged 20-24 years than among older women. ${ }^{1}$ Similar findings noted in present study. In present study $78 \%$ patients had primary infertility while rest $22 \%$ had secondary infertility. In a similar study Nayak et ${ }^{3}$ al observed $69 \%$ of cases with primary infertility and secondary infertility in $35 \%$ of cases. In $46 \%$ patients no abnormality noted in laparoscopy. Kavitha $\mathrm{G},{ }^{8}$ noted normal laparoscopic findings were seen in $42.4 \%$ patients while Bhandari S et $a l .{ }^{9}$ had $47.9 \%$ patients with normal findings. Rai et al. ${ }^{10}$ found that the most common abnormality found on Laparoscopy was endometriosis (32\%). Among uterine factors, numbers of patients with fibroids were observed in $17(8.5 \%)$ patients followed by congenital anomalies in 6 (3\%) patients. In present study PCOS (20\%), fallopian tube blockage (14\%) and ovarian cyst (9\%) were main findings. Similar results were seen in studies done by Puri et al.., ${ }^{11}$ they detected polycystic ovarian syndrome in $22 \%$ of cases while Kabadi and Harsha ${ }^{12}$ found ovarian pathology in $20.8 \%$ of cases.9 Laparoscopy can improve pregnancy rates and quality of life. It can also reduce costs of further fertility treatments by enhancing response to treatment, guiding further management, circumventing treatments that are of low benefit and avoiding complications like multiple pregnancies. ${ }^{13}$ Laparoscopy can reveal the presence of peritubal adhesions, periadnexal adhesions, tubal pathology, and endometriosis in $35-68 \%$ of cases even after normal HSG result. ${ }^{14}$ Apart from diagnostic purpose laparoscopy can help in adhesiolysis, ablation of endometriosis, ovarian drilling and ovarian cystectomy in same sitting. Hysteroscopy helps to pick up subtle changes in the form of small polyps, adhesions, and seedling fibroid due to magnification facility. Additionally, hysteroscopy-guided biopsy and therapeutic procedures like polypectomy, myomectomy, septal resection, and adhesiolysis can be done in the same sitting. In present study $19 \%$ females have abnormal findings on hysteroscopy. Patients underwent hysteroscopic adhesiolysis polypectomy, tubal cannulation, septal resection and myomectomy with good results. The high incidence of uterine factors can be attributed to current increased use of hysteroscopy in diagnosis of uterine anomalies and there by their correction as well. Surgical correction of septum improves the pregnancy outcome uterus with $80 \%$ term delivery, $5 \%$ preterm delivery, and $15 \%$ pregnancy loss. ${ }^{15}$ Polyps can cause sub-fertility and pregnancy loss by various mechanisms as interference with sperm transport, embryo implantation or through intrauterine inflammation or altered production of endometrial receptivity factors. In infertility patients apart from diagnostic aid many hysteroscopic procedures such as septal resection, polypectomy, submucous myoma resection, adhesiolysis and tubal cannulation can be done at the same time. Thus, hysteroscopy provides both diagnostic and therapeutic advantage in the same sitting with minimal complications. Abnormalities detected on laparoscopy were more common than those in hysteroscopy both in primary infertility group and in secondary infertility group. ${ }^{16}$ Similar findings were noted in present study. Certain conditions such as previous abdominal surgery, especially bowel surgery, and a history or presence of bowel/pelvic adhesions, severe endometriosis, pelvic infections, obesity, or excessive thinness. may increase the risk of intra and post-op complications. Proper patient selection and preoperative preparation is essential to reduce risk. Hysterolaparoscopy with chromopertubation is definitely superior in diagnosis of various kinds of tubal pathologies.

\section{CONCLUSION}

Hysterolaparoscopy is a definitive diagnostic tool for evaluation of female infertility. Hysterolaparoscopy is an effective, safe, reliable and minimal invasive tool in comprehensive evaluation of infertility and also good therapeutic intervention by experienced hands. Abnormalities missed on routine pelvic and radiological examination such as peritoneal endometriosis, adnexal adhesions, septate uterus, tubal blocks are diagnosed and corrected in one setting.

Conflict of Interest: None to declare Source of funding: Nil

\section{REFERENCES}

1. Mascarenhas MN, Flaxman SR, Boerma T, Vanderpoel S, Stevens GA. National, Regional, and Global Trends in Infertility Prevalence Since 1990: A Systematic Analysis of 277 Health Surveys. PLoS Med 2012; 9 (12): e1001356.

2. National Family Health Survey (NFHS-4), 2015-16, Government of India, Ministry of Health and Family Welfare.

3. Nayak PK, Mahapatra PC, Mallick JJ, Swain S, Mitra S, Sahoo J. Role of diagnostic hystero-laparoscopy in the 
evaluation of infertility: A retrospective study of 300 patients. J Hum Reprod Sci 2013;6:32-4.

4. Makled AK, Farghali MM, Shenouda DS. Role of hysteroscopy and endometrial biopsy in women with unexplained infertility. Arch Gynecol Obstet 2014;289:187-92.

5. Begum J, Samal S, Ghose S, Palai P, Samal R. Combined hysterolaparoscopy as an early option for initial evaluation of female infertility: A retrospective study of 135 patients. Int J Reprod Contracept Obstet Gynecol 2015;4:584-8

6. Pal M, Devgun P, Chalana H, Kaur H, Biswas A, Sen S. A study of prevalence and socio-demographic profile of infertile couples in field practice area of a tertiary care centre, Amritsar, Punjab, India. Int J Comm Med Pub Heal. 2017 Jan 5;3(6):1472-6.

7. Ganguly S, Sayeed U. Trends of Infertility and Childlessness in India: Findings from NFHS Data. Facts, views and vision in Ob Gyn. 2010;2:131-8.

8. Kavitha G, Renukadevi B. Role of hystero-laparoscopy with chromopertubation as a diagnostic cum therapeutic tool in evaluation and treatment of female infertility. The New Indian Journal of OBGYN. 2019; 6(1): 15-9

9. Bhandari S, Singh A, Agrawal P, Ganguli I. Findings in diagnostic laparoscopy in patients with unexplained infertility. Fertil Sci Res. 2015; 2(1): 29-33.
10. Rai A, Mishra MG. Diagnostic hystero-laparoscopy in work-up of female infertility. Int J Reprod Contracept Obstet Gynecol. 2017;6:2852-7.

11. Puri S, Jain D, Puri S, Kaushal S, Deol SK. Laparohysteroscopy in female infertility: A diagnostic cum therapeutic tool in Indian setting. Int J Appl Basic Med Res 2015;5:46-8.

12. Kabadi YM, Harsha B. Hysterolaparoscopy in the evaluation and management of female infertility. J Obstet Gynaecol India 2016;66 Suppl 1:478-81.

13. Moayeri SE, Lee HC, Lathi RB, Westphal LM, Milki AA, Garber AM. Laparoscopy in women with unexplained infertility: A cost-effectiveness analysis. Fertil Steril 2009;92:471-80.

14. Jahan S. Role of laparoscopy in infertility: review article. BIRDEM Med J 2012; 2:99-103.

15. Zhang E, Zhang Y, Fang L, Li Q, Gu J. Combined hysterolaparoscopy for the diagnosis of female infertility: A retrospective study of 132 patients in china. Mater Sociomed 2014;26:156-7.

16. Erhong Zhang, Yanan Zhang. Combined Hysterolaparoscopy for the Diagnosis of Female Infertility - a Retrospective Study of 132 Patients in China. 2014; 26:156-157.

\section{Source of Support: None Declared Conflict of Interest: None Declared}

